\title{
Modelling Analysis of Forestry Input-Output Elasticity in China
}

\author{
Guofeng Wang, ${ }^{1}$ Jiancheng Chen, ${ }^{1}$ and Xiangzheng Deng ${ }^{2,3}$ \\ ${ }^{1}$ School of Economics and Management, Beijing Forestry University, Beijing 100083, China \\ ${ }^{2}$ Institute of Geographic Sciences and Natural Resources Research, Chinese Academy of Sciences, Beijing 100101, China \\ ${ }^{3}$ Center for Chinese Agricultural Policy, Chinese Academy of Sciences, Beijing 100101, China \\ Correspondence should be addressed to Jiancheng Chen; chenjc_bjfu@hotmail.com
}

Received 22 April 2016; Revised 20 August 2016; Accepted 28 August 2016

Academic Editor: Piermaria Corona

Copyright (C) 2016 Guofeng Wang et al. This is an open access article distributed under the Creative Commons Attribution License, which permits unrestricted use, distribution, and reproduction in any medium, provided the original work is properly cited.

\begin{abstract}
Based on an extended economic model and space econometrics, this essay analyzed the spatial distributions and interdependent relationships of the production of forestry in China; also the input-output elasticity of forestry production were calculated. Results figure out there exists significant spatial correlation in forestry production in China. Spatial distribution is mainly manifested as spatial agglomeration. The output elasticity of labor force is equal to 0.6649 , and that of capital is equal to 0.8412 . The contribution of land is significantly negative. Labor and capital are the main determinants for the province-level forestry production in China. Thus, research on the province-level forestry production should not ignore the spatial effect. The policy-making process should take into consideration the effects between provinces on the production of forestry. This study provides some scientific technical support for forestry production.
\end{abstract}

\section{Introduction}

The reform of collective forest rights is another major revolution of the rural management system after land reform in China $[1,2]$. This reform has endowed farmers with partial forestry rights, so that these farmers are able to use their own forest resources and thereby gain revenue [3-5]. Thereby, in order to calculate the elasticity of labor, capital, and land inputs during the forestry growth, this study used a spatial econometric model to compute the contributions of all elements. The production flexibility and efficiency of capital are always a research hotspot [6-8]. Solow proposed an economy growth accounting model and applied new classical growth theory to economic accounting [9]. The existing research mainly focused on the input-output elasticity of agricultural production [10-12]. However, there is little research about forestry, a special agriculture department, and even the existing findings are controversial $[13,14]$. The researchers argued the output elasticity coefficients from the first, second, and third industries of forestry are 1.44, 0.72 , and 0.89 , respectively, during $1998-2005 ; 1.66,0.88$, and 0.81 , respectively, during 2006-2021; $1.82,0.96$, and 0.91 , respectively, during 2022-2030 [15]. These findings should be further validated from new perspectives and with new methods immediately.

This paper consists of four parts, the first part gives a brief description of relative research, the second part specifies the materials and methods used in this paper, the third part gives out results and discussion, and the last part is the conclusion part. Through this paper, we try to prove that the forestry production in one province influences that in another province.

\section{Materials and Methods}

2.1. Spatial Autocorrelation Test of Forestry Production. The forestry production in China is found with severe spatial differences and is largely correlated with the differences and fluidity of regional forestry resource $[16,17]$. Forestry production is modestly different among regions, but there may be spatial correlations among provinces [18-20]. In order to figure out the correlations and heterogeneity of provincelevel forestry production, we used global Moran's index:

$$
I=\frac{\sum_{i=1}^{n} \sum_{j=1}^{n} W_{i j}\left(Y_{i}-\bar{Y}\right)\left(Y_{j}-\bar{Y}\right)}{\sum_{i=1}^{n}\left(Y_{i}-\bar{Y}\right)^{2}},
$$


where $Y_{i}$ and $Y_{j}$ describe the observations of forestry output in regions $i$ and $j$, respectively, $n$ represents the number of regions, $\bar{Y}$ is the average observation of forestry outputs, and $W_{i j}$ is the spatial weight.

Under the circumstance of zero correlation, Moran'I was used to construct a standard normal index as follows:

$$
Z=\frac{(I-E(I))}{\sqrt{\operatorname{Var}(I)}}
$$

where $E(I)$ and $\operatorname{Var}(I)$ are decided by the spatial distribution of data and the arrangement of spatial lag matrix. When the $Z$-value is significant and positive, there is positive space correlation, indicating the presence of regional agglomeration among similar production regions. When the $Z$ value is significant but negative, there is negative significant correlation, indicating the presence of regional dispersity among similar production regions. When the $Z$-value is equal to zero, there exists random spatial distribution.

The global Moran's index can partially represent the space autocorrelation. However, owing to the repeated computation or mutual cancellation during computations, we used a local Moran'I index reflecting spatial autocorrelation, the local spatial correlation index, and Moran scatter diagram to further reveal whether or not there exists local spatial agglomeration. Local Moran's index is computed as follows:

$$
I_{i}=\frac{\left(Y_{i}-\bar{Y}\right)}{\sum_{i=1}^{n}\left(Y_{i}-\bar{Y}\right)^{2}} \cdot \sum_{j=1}^{n} W_{i j}^{\prime}\left(Y_{j}-\bar{Y}\right),
$$

where $W_{i j}^{\prime}$ is the standardized space weight matrix (the sum of each row is one). The expected value of local Moran's index $I_{i}$ is as follows:

$$
E_{i}\left(I_{i}\right)=-\frac{\sum_{j=1}^{n} W_{i j}}{(n-1)} .
$$

When $I_{i}$ is larger than the expected value of $E_{i}\left(I_{i}\right)$, there exists spatial agglomeration of similar forestry outputs around region $i$ or local space positive correlation. When $I_{i}$ is smaller than $E_{i}\left(I_{i}\right)$, there exists large differences among similar forestry outputs around region $i$ or local space negative correlation.

Moran scatter diagram shows the $2 \mathrm{D}$ scatter plot that visualizes $Z$ (a vector composed of the deviation between the observed value and the mean) and $W_{z}$ (space weighted average, or space lag vector). The vector-form global Moran'I index is computed as follows:

$$
I=\frac{n}{S} \cdot \frac{Z^{\prime} W_{z}^{\prime}}{Z^{\prime} Z}
$$

where $S_{0}=\sum_{i=1}^{n} \sum_{j=1}^{n} W_{i j}^{\prime}$; when $W_{i j}^{\prime}$ is the standardized space weight matrix, then $S_{0}=n$; at this moment, the global Moran's index is the linear regression slope of $W_{z}$ relative to $Z$. The first and third quadrants on Moran'I scatter plot represent the positive space correlations, while the second and fourth quadrants indicate the negative space correlations. Specifically, the first quadrant indicates the regions with large observed values are surrounded by largevalue regions; the second quadrant indicates the regions with small observed values are surrounded by large-value regions; the third quadrant indicates the regions with small observed values are surrounded by small-value regions; the fourth quadrant indicates the regions with large observed values are surrounded by small-value regions. The first and third quadrants represent typical positive space correlations, while the second and fourth quadrants indicate the local negative space correlations.

LISA (Local Indictors of Spatial Association) analysis is used to figure out the spatial differences in production. When LISA passes the significance test, there is local positive spatial autocorrelation, or this region is surrounded by regions with similar performance, called spatial agglomeration. When this region and its nearby regions are all found with large observed data, it is called a high-high region, and otherwise, it is called a low-low region.

\subsection{Selection of Weights for Forestry Space Autocorrelations.} The selection of spatial weight $W$ is associated with the results of spatial autocorrelation and spatial regression. $W_{i j}$ is defined as the contiguity or distance of any element from other elements. Currently, there are many types of weight matrices, including contiguity, $K$-nearest neighbors, and distance threshold. Specifically, contiguity matrices are divided into Rook (contiguity estimated from four directions of east, south, north, and west) and Queen (besides these four directions, it also involves other corners). As for $K$ nearest neighbors, several points closest to a test point are called its neighbors and each is assigned a weight 1 , and other points are given a weight 0 . Many researches figured out that different matrix may lead to different results, including spatial coefficient and the signs of the coefficient [21].

\subsection{Space Econometric Model in Forestry Economy Growth.} According to traditional economics, the economic growth mainly depends on two endogenous factors: labor and capital, but it is affected by technological progress, an exogenous factor. In this model, the land element is considered as an internal factor of economic growth. In other words, the output level $Y$ from each forestry region is decided by the labor input $L$, land input $D$, and capital input $K$. Then, this model is expressed as

$$
Y_{i}=A_{i} L_{i}^{\alpha} D_{i}^{\beta} K_{i}^{Y} e^{\varepsilon_{i}}
$$

where $Y_{i}$ is the forestry economic development level in region $i ; A_{i}$ is the technical level, $L_{i}$ is the labor input into forestry; $D_{i}$ is the land area; $K_{i}$ is the capital input; $\alpha, \beta$, and $\gamma$ are the corresponding output elasticity, respectively. If $\alpha+\beta+\gamma=1$, $\alpha+\beta+\gamma>1$, and $\alpha+\beta+\gamma<1$, then the return to scale is unchanged, increases, and gradually drops, respectively. Logarithm of both sides of (6) yields

$$
\ln Y_{i}=\ln A_{i}+\alpha \ln L_{i}+\beta \ln D_{i}+\gamma \ln K_{i}+\varepsilon_{i} .
$$


2.4. Space Lag Model (SLM) for Forestry Production Function. The basic model of forestry production does not involve space correlations. Taking spatial effects into account means the regional forestry production is affected not only by the local investment level, but also by the spillover effect from other nearby forestry regions. In this way, SLM is determined:

$$
\begin{aligned}
\ln Y_{i}= & \ln A_{i}+\rho W \ln Y_{i}+\alpha \ln L_{i}+\beta \ln D_{i}+\gamma \ln K_{i} \\
& +\varepsilon_{i},
\end{aligned}
$$

where $W$ is the space weight matrix and $W \ln Y$ is the weighted variable from a nearby forestry region. This model reflects the effects of regional forestry production from the input-output levels in nearby regions through the space effect.

2.5. Space Error Model (SEM) for Forestry Production. SEM takes into account the variables that may be ignored in the decision model, such as human capital, research level, and climate change. The space error model is used to measure the roles that may be played by the spatially interacting errors. SEM is expressed as

$$
\begin{aligned}
\ln Y_{i} & =\ln A_{i}+\alpha \ln L_{i}+\beta \ln D_{i}+\gamma \ln K_{i}+\varepsilon_{i}, \\
\varepsilon_{i} & =\lambda W \varepsilon_{i}+\mu_{i},
\end{aligned}
$$

where $W$ is the space weight matrix, and $\lambda$ measures the space error effect on regional forestry production due to observational errors.

2.6. Space Units and Data Sources. This study was targeted at 31 provinces or autonomous regions or municipality cities of Mainland China in 2013. The data were cited from China Forestry Statistical Yearbook 2013. The output variable was the total regional forestry production value. Regarding the release time of forestry statistical yearbooks, we used the forest areas in the statistics as the forestry area input. The number of labor forces by the end of 2013 was used as the regional labor force input. The fixed assets investment was used as capital input.

\section{Results and Discussion}

3.1. Global Moran's Index for Space Correlation of Forestry Production. To study the interferences of weight indices on the space effect, we used three space weight matrices, and through stepwise distance increment, we tested the attenuation effect of distance (Table 1). Clearly, global Moran'I index gradually decreases and shows the attenuation effect of distance. Moreover, Moran's index estimated from Queen1 weight matrix is 0.3685 , indicating the most significant space autocorrelation $(p<0.003)$ and the strong spatial dependence and evident space effect of forestry production.

3.2. Local Moran's Index and LISA Analysis for Space Correlation of Forestry Production. Table 1 uncovers the overall space autocorrelation in forestry production of each studied region, but local Moran's I cannot be identified by the global
TABLE 1: Global Moran's index for space autocorrelation for forestry productions in different regions.

\begin{tabular}{lcccc}
\hline & Moran's $I$ & Mean & SD & $p$ \\
\hline$W_{\text {ROOK1 }}$ & 0.3685 & -0.0249 & 0.1112 & 0.0040 \\
$W_{\text {ROOK2 }}$ & 0.0880 & -0.0247 & 0.0780 & 0.0700 \\
$W_{\text {ROOK3 }}$ & -0.0309 & -0.0318 & 0.0696 & 0.4660 \\
$W_{\text {Queen1 }}$ & 0.3685 & -0.0297 & 0.1041 & 0.0030 \\
$W_{\text {Queen2 }}$ & 0.0880 & -0.0324 & 0.0791 & 0.0780 \\
$W_{\text {Queen3 }}$ & -0.0309 & -0.0288 & 0.0712 & 0.4930 \\
$W_{K 1}$ & 0.1031 & -0.0233 & 0.1989 & 0.2410 \\
$W_{K 2}$ & 0.0950 & -0.0266 & 0.1454 & 0.1880 \\
$W_{K 3}$ & 0.2133 & -0.0284 & 0.1166 & 0.0290 \\
\hline
\end{tabular}

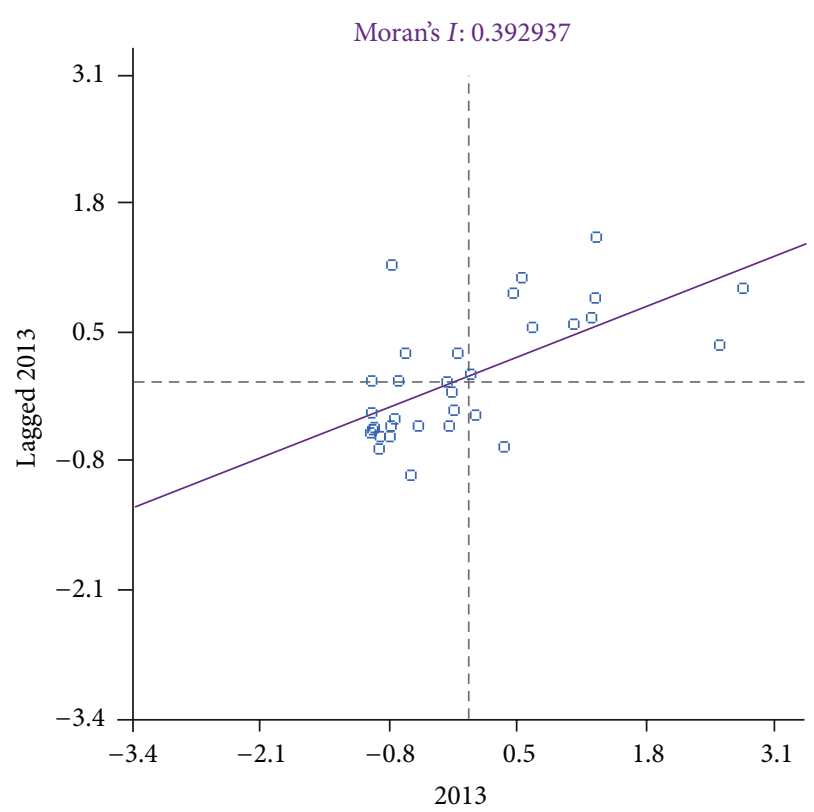

Figure 1: Local Moran's index based on $W_{\text {Queen1 }}$.

Moran'I index. To further portray the space correlation of forestry production, we used Moran scatter plot and LISA analysis to explore the local space characteristics of provincelevel forestry outputs (Figure 1).

The first quadrant involves Shandong, Anhui, Hubei, Zhejiang, Jiangxi, Hunan, Fujian, Guangxi, and Guangdong, which are all high-output provinces surrounded by highoutput provinces. The second quadrant involves Shanghai, Guizhou, Henan, Yunnan, and Chongqing, which are all low-output provinces surrounded by high-output provinces. The third quadrant involves Chongqing, Hebei, Jilin, Heilongjiang, Xinjiang, Shaanxi, Shanxi, Inner Mongolia, and Tibet, which are all low-output provinces surrounded by lowoutput provinces. The fourth quadrant involves Liaoning and Sichuan, which are both high-output provinces surrounded by low-output provinces. Clearly, the spatial differences of forestry outputs are very significant among all provinces in China, and the typical characteristics of positive local correlations and accumulation are very significant. 
TABLE 2: Local Moran's index based on space weight matrix $W_{\text {Queen1 }}$ as well as test results.

\begin{tabular}{|c|c|c|}
\hline Province & $I_{-} Y$ & $p_{-} y$ \\
\hline Beijing & 0.3633 & 0.27 \\
\hline Tianjing & 0.3745 & 0.23 \\
\hline Hebei & 0.0130 & 0.48 \\
\hline Shanxi & 0.2943 & 0.29 \\
\hline Neimenggu & 0.3060 & 0.14 \\
\hline Liaoning & -0.0611 & 0.39 \\
\hline Jilin & 0.0189 & 0.31 \\
\hline Heilongjiang & 0.0534 & 0.41 \\
\hline Shanghai & -0.0002 & 0.03 \\
\hline Jiangsu & -0.0382 & 0.04 \\
\hline Zhejiang & 0.0251 & 0.06 \\
\hline Anhui & 1.2997 & 0.01 \\
\hline Fujian & -0.1454 & 0.01 \\
\hline Jiangxi & 0.7301 & 0.02 \\
\hline Shandong & 0.6203 & 0.11 \\
\hline Henan & 0.3067 & 0.24 \\
\hline Hubei & -0.2512 & 0.49 \\
\hline Hunan & 0.3949 & 0.1 \\
\hline Guangdong & 2.3471 & 0.04 \\
\hline Guangxi & 0.6460 & 0.07 \\
\hline Hainan & 0.0000 & 0.01 \\
\hline Chongqing & -0.9785 & 0.46 \\
\hline Sichuan & 0.3683 & 0.01 \\
\hline Guizhou & 0.0096 & 0.31 \\
\hline Yunnan & 0.2826 & 0.45 \\
\hline Xizang & 1.0362 & 0.22 \\
\hline Shaanxi & 0.4459 & 0.15 \\
\hline Gansu & 0.4282 & 0.09 \\
\hline Qinghai & 0.1428 & 0.04 \\
\hline Ningxia & 0.2303 & 0.09 \\
\hline Xinjiang & 0.4537 & 0.01 \\
\hline
\end{tabular}

Note: $I_{-} Y$ is local Moran's index; $p_{-} Y$ is the adjoint probability of $I_{-} Y$.

The distribution of space autocorrelation patterns among the 31 provinces is as follows (Table 2): the significant highhigh regions include Shandong, Anhui, Jiangxi, Fujian, and Guangdong; the significant low-low regions are Shaanxi, Gansu, and Xinjiang. All other provinces are high-low areas or low-high areas or insignificant areas. It is indicated that the spatial distribution of forestry production in China is featured by a very evident center-periphery mode and by very significant local spatial agglomeration and space correlations.

\subsection{Space Econometric Analysis of Forestry Production Elas-} ticity. Then, a space econometric model was used to estimate the elasticity coefficients of labor, land, and capital inputs to province-level forestry production (Table 3 ). The residual errors of ordinary least squares (OLS) contain significant space correlations $(p<0.001)$. Then, to find out whether the residual errors originated from the internal SLM or SEM, we further validated the models. Results show SLM is very significant, but it is not significant versus SEM. Thus, SEM is more significant.

To identify the effects and contributions of different input elements to forestry production, we built an SEM using
TABLE 3: Space correlation OLS test based on space weight matrix $W_{\text {Queen1 }}$.

\begin{tabular}{|c|c|c|c|c|}
\hline \multirow{2}{*}{ Test } & \multicolumn{2}{|c|}{ Trivariate function } & \multicolumn{2}{|c|}{ Bivariate function } \\
\hline & Index & $p$ & Index & $p$ \\
\hline Moran'I (error) & 4.8671 & 0.0000 & 4.7938 & 0 \\
\hline $\begin{array}{l}\text { Lagrange } \\
\text { multiplier (lag) }\end{array}$ & 0.335 & 0.5628 & 0.4905 & 0.4837 \\
\hline Robust LM (lag) & 0.2234 & 0.6365 & 0.1971 & 0.6571 \\
\hline $\begin{array}{l}\text { Lagrange } \\
\text { multiplier } \\
\text { (error) }\end{array}$ & 14.9747 & 0.0001 & 16.3942 & 0 \\
\hline $\begin{array}{l}\text { Robust LM } \\
\text { (error) }\end{array}$ & 14.8631 & 0.0001 & 16.1007 & 0 \\
\hline $\begin{array}{l}\text { Lagrange } \\
\text { multiplier } \\
\text { (SARMA) }\end{array}$ & 15.1981 & 0.0005 & 16.5912 & 0.0002 \\
\hline
\end{tabular}

three elements that decide agricultural production (Table 4), estimating the elasticity coefficients of labor force, land, and capital to the forestry output of each province. First, the forestry production involving the three elements was analyzed via OLS. Results show the fitting degree of SEM is 0.9215, with smallest Akaike information criterion (AIC, 93.93) and Schwarz criterion (SC, 99.79), indicating SEM is most suitable.

Results show neither the estimations nor the significance levels of output elasticity are always the same for any of the three elements, in both OLS and space economic models. The output elasticity of forestry labor from the bivariate SEM is $0.6492(p=0.0058)$, while the output elasticity from forestry capital is $0.6603(p=0.003)$.

As shown in Table 4, the output elasticity estimated from OLS is the highest from capital (0.8412), indicating a tendency to overestimation. The output elasticity from capital is 0.3968 , with a tendency to underestimation. Thus, the elasticities from capital and labor outputs make the SEM more suitable.

The trivariate model also involves the land input, but the forestry production measured from this variable is not very significant $(p>0.1)$; thus, it plays a negative role.

It should be noted that the model used here is based on space economic theory. This method indicates that the space effect should not be ignored. However, the estimation results only reveal the state-level standard but do not take into account the regional differences. In the future, more accurate and precise economic models are needed. Another thing that may be a limit for this paper is that, as to limitation of the data and observations, the result may vary according to different situations, which needs future study.

\section{Conclusions}

Here we used the sectional data of province-level forestry input-output in 2013 in China. Then, the Moran'I with space autocorrelation and the local Moran'I index with space correlation were used to portray a forestry production spatial distribution mode involving 31 provinces in China. Then, 
TABLE 4: Different regression models based on space weight matrix $W_{\text {Queen1 }}$.

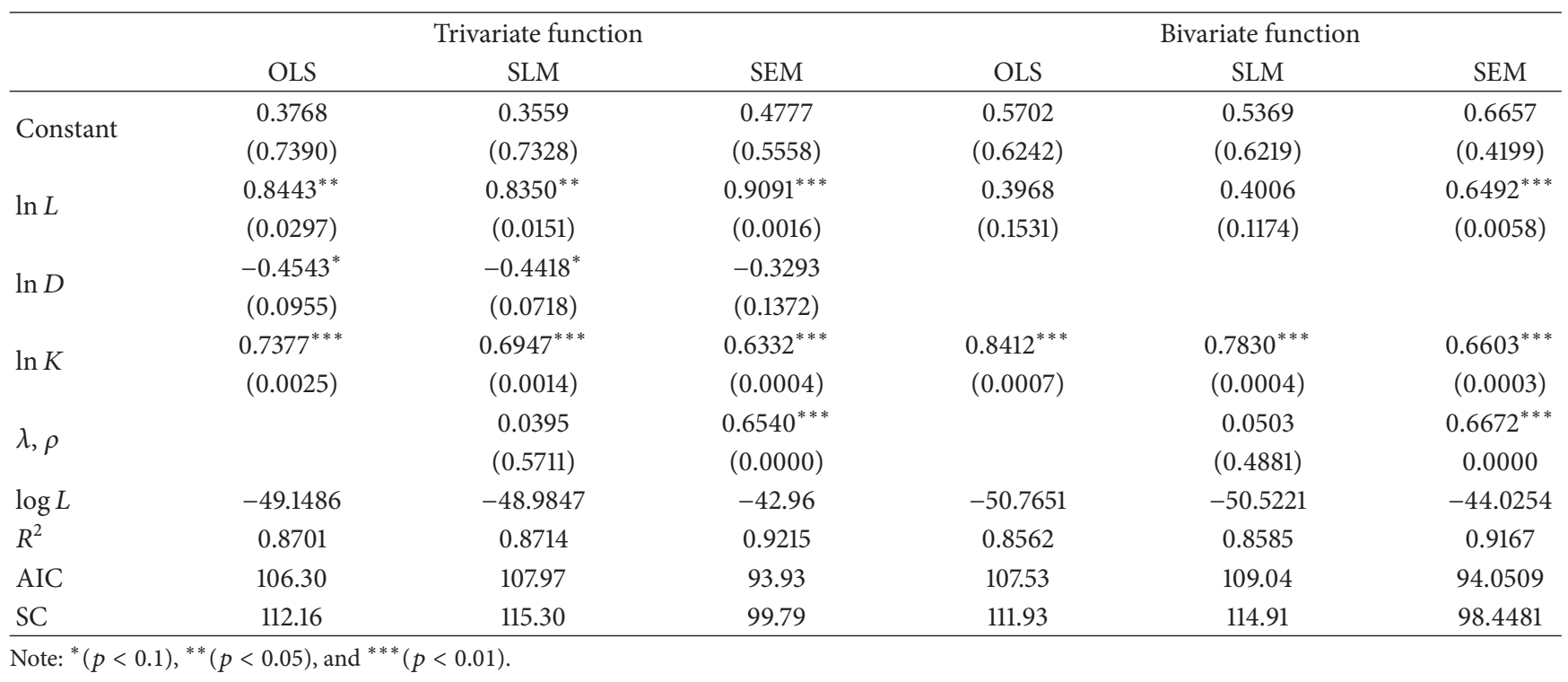

SLM and SEM were used to estimate the elasticity coefficients of province-level forestry input-output. We find the forestry outputs from the 31 provinces are significantly autocorrelated both globally and locally, and the province-level space correlations and heterogeneity are all very significant. The labor force and capital are the detrimental factors on the regional forestry production, but the contributions from lands are not very obvious. The spillover effect of spatial errors plays a significant role in the forestry production of adjacent provinces. In other words, the forestry production of a province, through the spillover of error items, influences the growth of forestry output in nearby provinces. Similarly, it is indicated that SEM is a very suitable space econometric model.

The global and local Moran'I space autocorrelation tests and space econometric estimations all indicate that the spatial effect cannot be ignored in the study on province-level forestry production. With the input-output model, we find the test results of SEM in the provincial production function are all better than OLS, and the precision of regression coefficients is higher. Thus, space autocorrelation method is an efficient method for analysis of forestry production. The space econometric model is more objective in exploration of influence factors.

From the perspective of policy implications, due to the existence of space error spillover effect in forest products and the remaining forestry output, the forestry production behaviors in nearby provinces will affect the agricultural production behaviors of the tested province. The time "incentive" effect in decision-making for regional agricultural production will influence the production game competition among nearby provinces and finally impact the input scales and allocation efficiency of province-level forestry production elements. Thus, the formulation of relevant forestry policies should not ignore the transverse cross-effect among provincial forestry production, and should take into account the interactions of forestry production among nearby provinces.
A regional coordination mechanism should be established to coordinate the rational flow of forestry production elements, to improve the space complementarity and space allocation efficiency of elements, and to promote the regional forestry production ability.

\section{Competing Interests}

The authors declare that there is no conflict of interests regarding the publication of this article.

\section{Acknowledgments}

This research was supported by the National Natural Science Foundation of China for Distinguished Young Scholars (Grant no. 71225005), the Key Project in the National Science \& Technology Pillar Program of China (Grant no. 2013BACO3B00), and the funding support from the Institute of Geographic Sciences and Natural Resources Research, Chinese Academy of Sciences (Grant no. 2012ZD008).

\section{References}

[1] A. E. Duchelle, M. Cromberg, M. F. Gebara et al., "Linking forest tenure reform, environmental compliance, and incentives: lessons from REDD+ initiatives in the Brazilian Amazon," World Development, vol. 55, pp. 53-67, 2014.

[2] A. M. Larson, D. Barry, and G. Ram Dahal, "New rights for forest-based communities? Understanding processes of forest tenure reform," International Forestry Review, vol. 12, no. 1, pp. 78-96, 2010.

[3] P. Jagger, Forest Incomes after Uganda's Forest Sector Reform: Are the Rural Poor Gaining? International Food Policy Research Institute (IFPRI), Washington, DC, USA, 2008.

[4] C. Wang, Y. Wen, and J. Wu, "The Socio-economic effect of the reform of the collective forest rights system in Southern China: 
a case of Tonggu County, Jiangxi Province," Small-Scale Forestry, vol. 13, no. 4, pp. 425-444, 2014.

[5] Y. Zhu, H. Lan, D. A. Ness et al., "Carbon trade, forestry land rights, and farmers' livelihood in rural communities in China," in Transforming Rural Communities in China and Beyond: Community Entrepreneurship and Enterprises, Infrastructure Development and Investment Modes, pp. 61-91, Springer International Publishing, Berlin, Germany, 2015.

[6] P. C. Beukes, P. Gregorini, A. J. Romera, G. Levy, and G. C. Waghorn, "Improving production efficiency as a strategy to mitigate greenhouse gas emissions on pastoral dairy farms in New Zealand," Agriculture, Ecosystems \& Environment, vol. 136, no. 3-4, pp. 358-365, 2010.

[7] J.-P. Chavas, R. Petrie, and M. Roth, "Farm household production efficiency: evidence from the Gambia," American Journal of Agricultural Economics, vol. 87, no. 1, pp. 160-179, 2005.

[8] U. Moallem, "Future consequences of decreasing marginal production efficiency in the high-yielding dairy cow," Journal of Dairy Science, vol. 99, no. 4, pp. 2986-2995, 2016.

[9] R. M. Solow, "Technical change and the aggregate production function," The Review of Economics and Statistics, vol. 39, no. 3, pp. 312-320, 1957.

[10] G. Holloway, D. Lacombe, and J. P. LeSage, "Spatial econometric issues for bio-economic and land-use modelling," Journal of Agricultural Economics, vol. 58, no. 3, pp. 549-588, 2007.

[11] B. Hu and M. McAleer, "Estimation of Chinese agricultural production efficiencies with panel data," Mathematics and Computers in Simulation, vol. 68, no. 5-6, pp. 474-483, 2005.

[12] M. Lio and M.-C. Liu, "Governance and agricultural productivity: a cross-national analysis," Food Policy, vol. 33, no. 6, pp. 504-512, 2008.

[13] D. P. Faith, P. A. Walker, J. R. Ive, and L. Belbin, "Integrating conservation and forestry production: exploring trade-offs between biodiversity and production in regional land-use assessment," Forest Ecology and Management, vol. 85, no. 1-3, pp. 251-260, 1996.

[14] J. J. Troncoso and R. A. Garrido, "Forestry production and logistics planning: an analysis using mixed-integer programming," Forest Policy and Economics, vol. 7, no. 4, pp. 625-633, 2005.

[15] M. Ma, T. Haapanen, R. B. Singh, and R. Hietala, "Integrating ecological restoration into CDM forestry projects," Environmental Science \& Policy, vol. 38, pp. 143-153, 2014.

[16] Z. Li, X. Deng, Q. Shi, X. Ke, and Y. Liu, "Modeling the impacts of boreal deforestation on the near-surface temperature in European Russia," Advances in Meteorology, vol. 2013, Article ID 486962, 9 pages, 2013.

[17] X. W. Yu, H. Y. Liu, Y. C. Yang, X. Zhang, and Y. W. Li, "Geoserver based forestry spatial data sharing and integration," Applied Mechanics and Materials, vol. 295-298, pp. 2394-2398, 2013.

[18] X. Deng, J. Huang, E. Uchida, S. Rozelle, and J. Gibson, "Pressure cookers or pressure valves: do roads lead to deforestation in China?" Journal of Environmental Economics and Management, vol. 61, no. 1, pp. 79-94, 2011.

[19] G. Fu, M. Shah, E. Uchida et al., "Impact of the Grain for Green program on forest cover in China," in Proceedings of the Annual Meeting, Agricultural and Applied Economics Association, Washington, DC, USA, August 2013.

[20] F. Y. T. S. L. Zengyuan, "Application of spatial statistic analysis in forestry," Scientia Silvae Sinicae, vol. 3, article 25, 2004.
[21] L. P. Sun, "Spatial analysis of the evolvement of urban and rural economic disparity in yunnan province, China," Asian Agricultural Research, vol. 2, no. 6, 2010. 

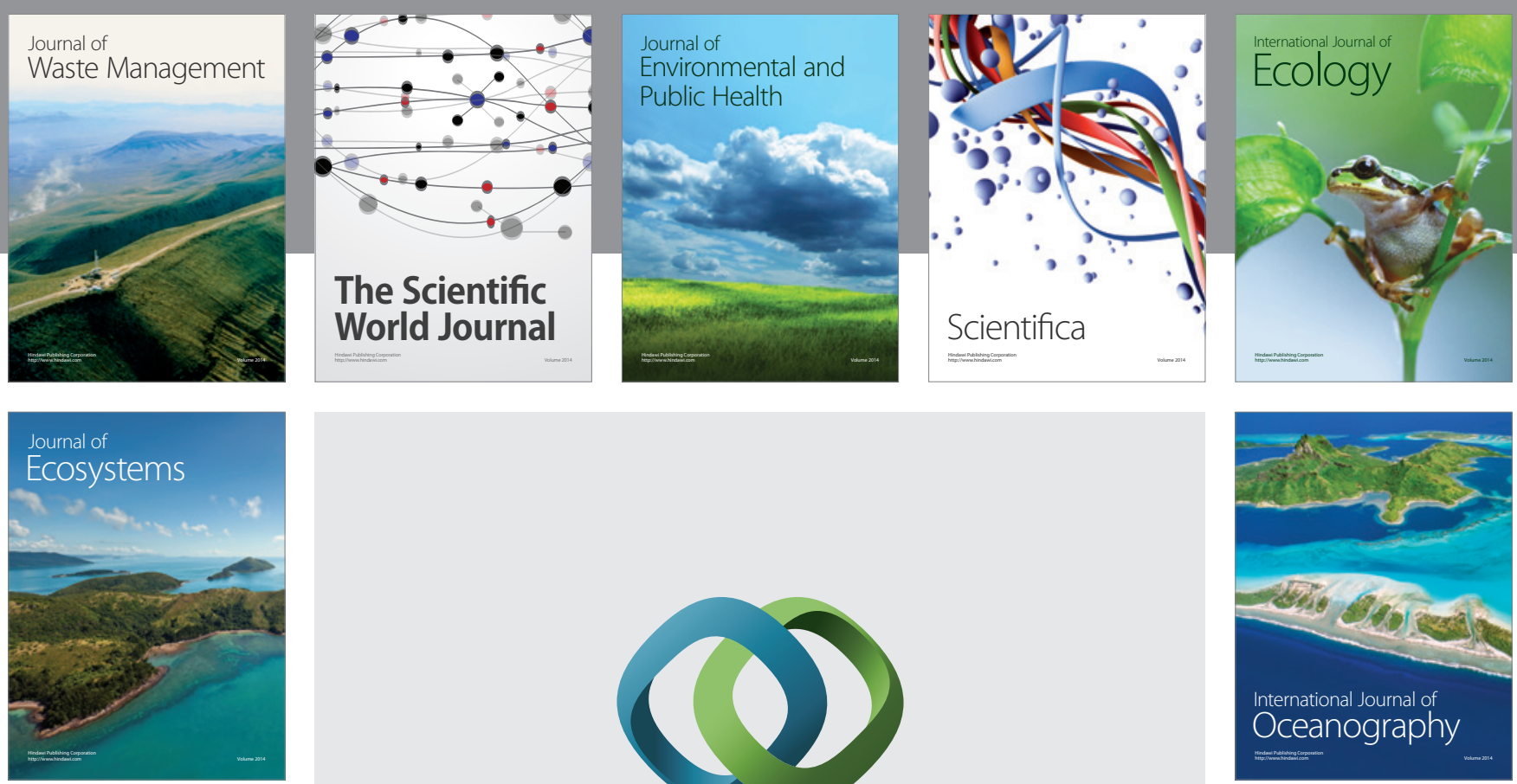

The Scientific World Journal
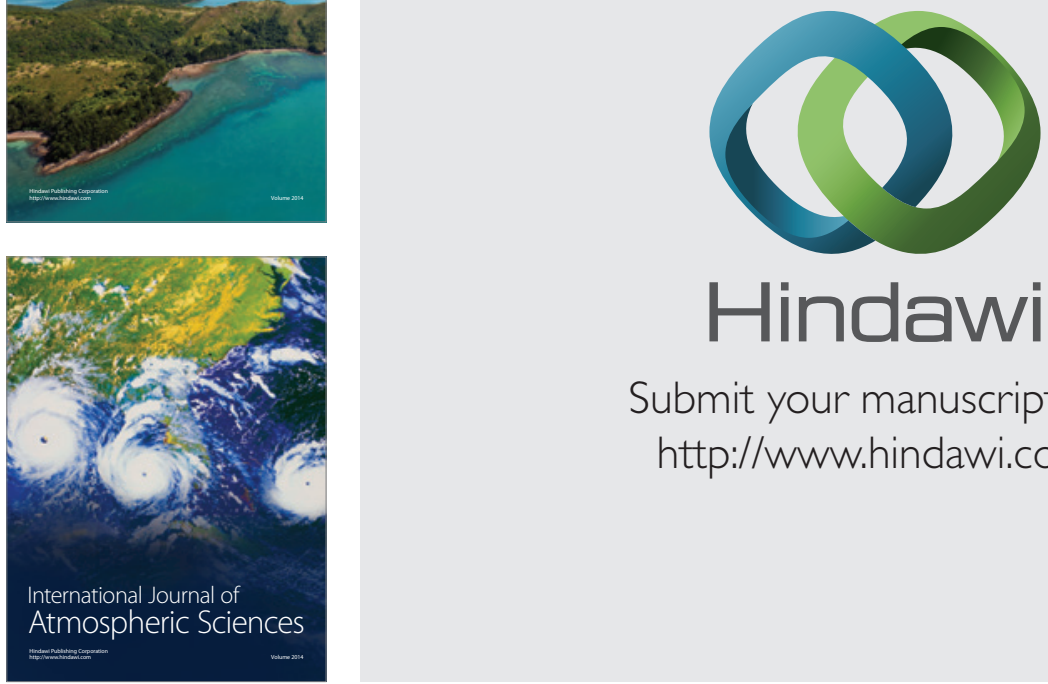

\section{Hindawi}

Submit your manuscripts at

http://www.hindawi.com
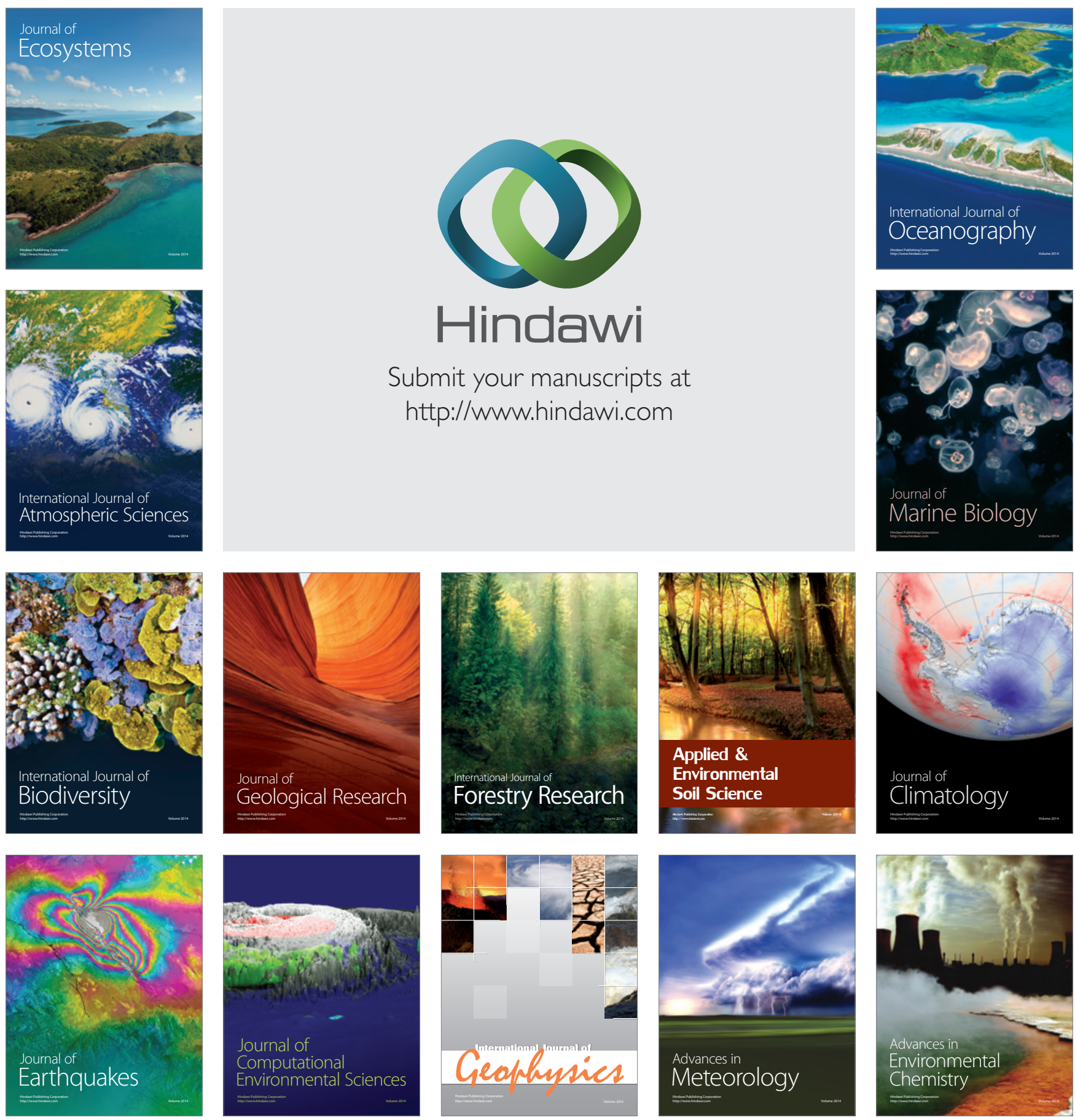